

Revista da Universidade Vale do Rio Verde ISSN: 1517-0276 / EISSN: 2236-5362 Vol. 16 | n. 1 | Ano 2018

Gabriel Najar Machado de Sousa e Silva Universidade do Oeste de Santa Catarina gabriel_najar@hotmail.com

César Augustus Winck

Universidade do Oeste de Santa Catarina cesar.winck@unoesc.edu.br

\section{BRONQUITE INFECCIOSA AVIÁRIA: REVISÃO DE LITERATURA}

\section{RESUMO}

A bronquite infecciosa aviária é uma doença respiratória viral aguda, altamente contagiosa, que acomete galinhas de diferentes idades. Ela é altamente contagiosa devido ao fato de o vírus se disseminar rapidamente entre as aves; não há necessidade de vetores para sua transmissão, aves doentes infectam outras hígidas por contato direto ou indireto. O vírus causador da doença é do gênero Coronavirus e pertencente à família Coronariviridae. Apesar de ter predileção pelo trato respiratório, ele causa queda na produção e qualidade de ovos em galinhas; já em frangos de corte, causa queda de desempenho. A doença pode ser considerada endêmica em todos os países que tenham produção de aves. Diversos surtos têm ocorrido no Brasil e isso fez com que a bronquite infecciosa aviária tenha se tornado a principal doença avícola em território nacional. Devido aos diferentes sorotipos e as características mutantes do agente etiológico, há dificuldade na elaboração de planos de vacinação. Em consequência do aumento da produção avícola nacional se torna necessária à criação de planos de biosseguridade que sejam viáveis e extremamente eficazes.

Palavras-chave: Agronegócio. IBV. Galinhas. Avicultura. Coronavirus.

\section{AVIAN INFECTIOUS BRONCHITIS: LITERATURE REVIEW}

\begin{abstract}
The avian infectious bronchitis is an acute viral respiratory disease, highly contagious, affecting chickens of different ages. It is highly contagious due to the fact that the virus spread rapidly among birds; no need to vectors for transmission, sick birds infects other otherwise healthy by direct or indirect contact. The virus that causes the disease is the Coronavirus genus and belongs to Coronariviridae family. Despite having predilection for the respiratory tract, it causes a fall in production and quality of eggs in chickens; already in broilers, cause performance degradation. The disease is considered endemic in all countries that have poultry production. Several outbreaks have occurred in Brazil and this has caused the avian infectious bronchitis has become the leading poultry disease in the country. Due to the different serotypes and the changing characteristics of the etiological agent, there is difficulty in developing vaccination plans. As a result of increase in domestic poultry production it becomes necessary to create biosecurity plans that are viable and extremely effective.
\end{abstract}

Keywords: Agribusiness. AIB. Chicken. Aviculture. Coronavirus. 


\section{INTRODUÇÃO}

O setor avícola do Brasil está em destaque no mundo todo, considerando desenvolvimento tecnológico dos últimos anos. O país está entre os maiores produtores e exportadores de carne de frango, e a produção de ovos não fica atrás, devido a considerável demanda do mercado interno pelo produto, promovendo avanços na área. Por ser uma importante fatia da economia nacional, é necessário que os profissionais da área avícola estejam atualizados quanto às doenças presentes no plantel nacional, e elaborem programas de controle sanitários eficientes.

A Bronquite infecciosa aviária (IBV) é uma doença viral que acomete aves da espécie Gallus gallus. Ela foi descrita pela primeira vez em 1931, na cidade de Dakota do Norte (EUA), e em 1933, dois pesquisadores notificaram uma doença idêntica, mas diagnosticaram-na como laringotraqueíte infecciosa.

Já em 1936, por meio de estudos, comprovou-se que o agente da bronquite infecciosa era distinto do vírus da laringotraqueíte, sendo assim, denominado de vírus da bronquite infecciosa (IBV). No Brasil, o primeiro diagnóstico da bronquite infecciosa aviária foi em 1957, no Estado de Minas Gerais.

A bronquite infecciosa aviária tem importância econômica no setor avícola, pois afeta frango de corte, poedeiras comerciais e reprodutoras. Em frangos de corte causa queda no ganho de peso com consequente piora da conversão alimentar, além de elevação da mortalidade e condenação de carcaças no abatedouro. Nas galinhas de postura comercial e reprodutoras causa redução na produção de ovos e diminui a qualidade interna e externa destes.
O objetivo deste estudo bibliográfico é apresentar a importância da bronquite infecciosa aviária, expondo os principais pontos como: etiologia, epidemiologia, sinais clínicos, patogenia, imunidade, diagnóstico e controle da doença.

\section{REVISÃO DE LITERATURA}

\section{AVICULTURA NO BRASIL}

$\mathrm{Na}$ última década a avicultura brasileira apresentou considerável desenvolvimento, e a carne de frango alcançou mercados mais exigentes, isto devido a máxima produtividade associada com baixos custos e qualidade do produto final (MAPA, 2017).

O desenvolvimento do setor se deve também, ao aumento do consumo per capita de carnes, que em 2005 era de 35,48 kg/hab., e em 2014, esse número elevou-se $20 \%$, alcançando 42,78kg/hab.; e também, pelo aumento nos valores das exportações nacionais de carnes e derivados de frango. O Brasil tornou-se líder mundial na exportação de carne de frango (Tabela 1) superando os EUA e a União Europeia.

Tabela 1 - Exportação de carne de frango (2014)

\begin{tabular}{|l|r|}
\hline \multicolumn{1}{|c|}{ País } & \multicolumn{1}{c|}{$\begin{array}{c}\text { Exportação } \\
\text { (milhões de ton.) }\end{array}$} \\
\hline Brasil & 4.099 \\
\hline EUA & 3.297 \\
\hline União Europeia & 1.100 \\
\hline Tailândia & 540 \\
\hline China & 440 \\
\hline Outros & 1.501 \\
\hline TOTAL & $\mathbf{1 0 . 9 7 7}$ \\
\hline
\end{tabular}

Fonte: Adaptado de ABPA (2016)

No ranking da produção de carne de frango o Brasil ocupa a terceira posição, sendo superado apenas por EUA e China (Tabela 2) (ABPA). 
Tabela 2 - Produção mundial de carne de frango (2014)

\begin{tabular}{|l|r|}
\hline \multicolumn{1}{|c|}{ País } & $\begin{array}{c}\text { Exportação (em milhões } \\
\text { de ton.) }\end{array}$ \\
\hline EUA & 17.254 \\
\hline China & 13.000 \\
\hline Brasil & 12.691 \\
\hline União Europeia & 10.070 \\
\hline Índia & 3.725 \\
\hline Outros & 29.337 \\
\hline TOTAL & $\mathbf{8 6 . 0 7 7}$ \\
\hline
\end{tabular}

Fonte: Adaptado de ABPA (2016)

Nas granjas brasileiras, os efetivos programas de biosseguridade, a seleção genética, associados ao manejo e ambiência, garantem o status sanitário livre de doenças de notificação obrigatória. Por trás da cadeia produtiva estão presentes diversas agroindústrias, espalhadas por Estados brasileiros. (ABPA)

A maior parte da produção de frangos de corte está ligada ao sistema de integração e de cooperativas, e estima-se que mais de $90 \%$ da produção de carne de frango produzida no Brasil, ocorra por meio dessas estruturas produtivas. $\mathrm{O}$ sistema de integração é representado pelas agroindústrias que detêm praticamente todo o processo produtivo, desde a produção do ovo fértil até o abate (MENDES e SALDANHA, 2004).

Este método de produção integrado, envolve a empresa e o produtor, e cada um precisa cumprir com a sua parte no processo. A integradora deve fornecer os pintos, a ração, a assistência técnica, medicamentos necessários, o abate e a comercialização; e o produtor deve oferecer as instalações e a mão de obra (MENDES e SALDANHA, 2004).

Considerando a importância do setor avícola nacional tanto no contexto nacional e mundial, e a necessidade da padronização e normatização das ações de acompanhamento sanitário relacionadas ao setor avícola, em 19 de setembro de 1994, pela Portaria Ministerial $n^{\circ}$ 193, foi consolidado o Programa Nacional de Sanidade Avícola (PNSA), do Ministério da Agricultura Pecuária e do Abastecimento (MAPA). O PNSA criou programas sanitários para prevenir e controlar a doença de Newcastle, Micoplasmoses, Salmoneloses e Influenza aviária (MAPA, 2017).

\section{HISTÓRICO DA DOENÇA}

A doença foi descrita primeiramente nos EUA, em 1931, por Schalk e Hawn sendo observada na população de pintos de 2 a 21 dias de vida. As lesões macroscópicas encontradas nesses animais foi exsudato na traqueia $\mathrm{e}$ brônquios, e além das lesões, a doença caracterizou-se por elevada mortalidade das aves (LIMA, 2007).

A bronquite infecciosa aviária também era comum em aves mais velhas, era observada redução na produção de ovos. Rapidamente a doença se espalhou pelos EUA e sem demora passou a ser relatada em outros países; a bronquite infecciosa aviária é considerada uma doença cosmopolita (LIMA, 2007).

No Brasil a doença foi diagnosticada no ano de 1957, em Minas Gerais. Surgiu de forma branda, como uma infecção suave, que se mesclou a diversas outras infecções já existentes, como as de Newcastle e laringotraqueíte infecciosa (HIPÓLITO et al. 1979).

\section{ETIOLOGIA DA DOENÇA}

$\mathrm{O}$ vírus causador da bronquite infecciosa aviária pertence ao gênero Coronavirus, família Coronaviridae e ordem Nidovirales. Este nome se dá devido às projeções pedunculadas que 
revestem o envoltório do vírion, essas são conhecidas como espículas ou peplômeros (MONTASSIER et al., 2008; CUBILLOS, 2009). O gênero é separado de acordo com suas características genéticas e antigênicas, ele pertence ao grupo 3. Os patógenos pertencentes a esse grupo acometem apenas aves (JACKWOOD et al., 2003; MCKINLEY et al., 2008).

$\mathrm{O}$ vírus é pleomórfico com predominância de partículas esféricas e seu tamanho é de 120nm de diâmetro (RESENDE, 2003). Segundo Lima (2007), diferentes espécies do Coronavirus revelaram presença de vírions esféricos de 60 a $160 \mathrm{~nm}$ de diâmetro, revestidos por envelope lipídico duplo. Devido à presença desse envelope lipídico, é extremamente sensível às condições ambientais e aos desinfetantes mais comuns utilizados (ROCHA, 2000).

O ácido nucleico do Coronavirus é um RNA com hélice simples que pode ser comprovado pela supressão da replicação viral após o tratamento com DL-parafluorpentalanina, que inibe a síntese do RNA. Já a síntese do DNA é inibida pela aminopterina, mas essa inibição não prejudica na replicação do vírus (LIMA, 2007).

O genoma viral é composto por quatro proteínas: nucleoproteína $(\mathrm{N})$, proteína da membrana $(\mathrm{M})$, spikes $(\mathrm{S})$ e proteína do envelope (E). Os anticorpos direcionados à proteína $\mathrm{N}$ são os primeiros a serem detectados após a infecção, porém não estão relacionados com a proteção. A proteína $\mathrm{S}$ é dividida em duas partes, S1 e S2; a primeira tem importante papel para a entrada do vírus na célula hospedeira; e a segunda auxilia $\mathrm{S} 1$ por ter estrutura mais rígida (CAVANAGH et al., 1992; CAVANAGH, 2007; MCKINLEY et al., 2008). A proteína $\mathrm{M}$ permite que o vírus faça recombinação entre diferentes sorotipos. Essa fácil recombinação permite que o agente tenha boa vantagem evolutiva, pois consegue driblar os anticorpos do hospedeiro e se estabelecer no organismo (RESENDE, 2003).

\section{SOROTIPOS DO VÍRUS}

Após 1956 descobriu-se que a bronquite infecciosa aviária é causada por mais de um tipo antigênico de vírus. Primeiramente foi representada por uma amostra patogênica, Massachusetts 41, e por outra não patogênica, Baudette 42. Em seguida foram descobertas, através de teste de soroneutralização em embrião de galinha, as variantes antigênicas Connecticut e Massachusetts. Desde então se isolou grande número de variantes, que apresentam diferentes propriedades sorológicas, biológicas e tropismo (LIMA, 2007).

A importância de identificar e conhecer os diferentes sorotipos são para poder controlar a doença, pois as imunidades primária e secundária estão relacionadas a um sorotipo e não tem relação cruzada com outro (LIMA, 2007).

\section{EPIDEMIOLOGIA E PATOGENIA DA DOENÇA}

O vírus da bronquite infecciosa aviária está presente em praticamente todos os países, com exceção da Albânia, Groelândia, Letônia, Mongólia, Geórgia, St. Kitts e Nevis, São Vicente e Granadinas, Trinidad e Tobago e Tajiquistão (OIE, 2015).

O Gallus domesticus era o único hospedeiro da bronquite infecciosa aviária, mas agora se sabe que perus e faisões também podem se infectar com esta doença. As aves são 
suscetíveis em qualquer idade, porém sinais clínicos são mais severos em aves jovens. Linhagens resistentes ou sensíveis são igualmente suscetíveis à infecção inicial, mas na linhagem resistente a recuperação se dá de forma mais acelerada (DHINAKAR e JONES, 1997; CUBILLOS, 2009).

A transmissão ocorre por contato direto ou indireto de ave doente para ave hígida, sem a necessidade de vetores para a disseminação. O vírus pode ser transmitido durante qualquer estágio da doença. Dentro de um lote de aves a transmissão ocorre num período de 18 a 96 horas. O período de incubação é de 48 a 96 horas, podendo variar de 1 a 11 dias (LIMA, 2007).

O vírus entra no organismo por inalação ou via conjuntival, se multiplicando rapidamente no trato respiratório, que é o local de predileção dele. Sua replicação ocorre nas células epiteliais, células secretoras de muco, células epiteliais dos pulmões e sacos aéreos. Além de lesões no trato respiratório, causa lesões no trato reprodutivo, digestivo e urinário (DHINAKAR E JONES, 1997; CAVANAGH, 2003; CUBILLOS, 2009).

Vários patógenos que acometem as aves podem potencializar a bronquite infecciosa, tornando-a mais severa e duradoura, além disso, pode haver interação desses agentes com o vírus vacinal, também agravando a doença (MATTHIJS et al., 2009).

\section{SINAIS CLÍNICOS DA DOENÇA}

Os sinais clínicos variam de acordo com o sistema acometido. No sistema respiratório há dificuldade para respirar e a ave apresenta sinais como tosse, espirro, estertor traqueal, conjuntivite, descarga nasal e inflamações nos seios infraorbitários. Os animais se agrupam próximos à fonte de calor, ocorre queda no consumo de ração e, consequentemente, perda de peso. Em casos severos as aves apresentam forte diarreia, causando piora na qualidade da cama de aviário. Pode ocorrer aerossaculite por infecções secundárias ( $E$. coli e micoplasma), fator que agrava o quadro clínico do animal e eleva a morbidade e mortalidade (DHINAKAR e JONES, 1996; CAVANAGH, 2003; CUBILLOS, 2009).

Em aves jovens, o vírus atinge facilmente o sistema renal, faz sua replicação nos túbulos proximais e distais. Em infecções mais graves ocorre doença renal severa, causando nefrite, nefrose, urolitíase e gota. A mortalidade pode chegar a 30\% (WINTERFIELD e ALBASSAM, 1984; CHEN et al., 1996; JORDAN, 1998).

Em aves jovens de postura comercial ou reprodutoras, o vírus atinge o sistema reprodutor, causando deficiência no desenvolvimento do oviduto. As aves ovulam normalmente e o ovo se deposita na cavidade abdominal, podendo ser reabsorvido ou causar peritonite. Nas aves adultas, pode causar severo declínio na produção e na qualidade dos ovos. Essa severidade varia de acordo com o período de postura e virulência do vírus (MUNER 1988; JORDAN, 1998; CAVANAGH 2003).

\section{PATOLOGIA DA DOENÇA}

Lesões macroscópicas

Pintinhos apresentam exsudato seroso, catarral ou caseoso na traqueia e nas vias aéreas, sacos aéreos são opacos e também contêm exsudato caseoso. Fêmeas jovens apresentam diferentes graus de desenvolvimento anormal do oviduto. Já em poedeiras maduras, quando o 
oviduto é lesionado, ocorre diminuição ou oclusão do istmo e magno. $\mathrm{Na}$ ocorrência de infecção secundária por $E$. coli a ave pode apresentar pneumonia, além da aerossaculite (JORDAN, 1998; CUBILLOS 2009; DWARS, 2009).

\section{Lesões microscópicas}

No trato respiratório há descamação das células epiteliais e das células secretoras de muco, havendo infiltração intensa por células linfoides na lâmina própria. Nos sacos aéreos acometidos são observadas descamações das células epiteliais, edema e exsudato fibrinoso. Em nível renal ocorre principalmente nefrite intersticial, descamação do epitélio tubular, degeneração granulosa e infiltração de heterofilos no interstício durante a fase aguda da doença (CHEN, 1996; DHINAKAR e JONES, 1997; JORDAN, 1998; CHOUSALKAR et al., 2009).

\section{IMUNIDADE}

Diferentes tipos de imunidade protegem contra o vírus da bronquite. Existe a imunidade de origem materna, imunidade local ou de mucosa, mediada por células e humoral. A imunidade materna protege aves contra infecções precoces, mas sua duração é baixa; na imunidade local há proteção em combate à infecção respiratória primária; a imunidade mediada por célula tem papel fundamental na resposta contra a infecção, já que a imunidade humoral não tem correlação com a proteção (DI FABIO e ROSSINI, 2000; CUBILLOS, 2009).

Existem três classes de imunoglobulinas envolvidas na resposta imune, IgM, IgG e IgA. IgM é o primeiro anticorpo a aparecer após a infecção, pode ser detectado entre 6 e 9 dias, sua presença é indicativa de infecção recente ou de vacinação. IgG está em maior número no soro após a infecção, por isso é utilizada na sorologia para diagnóstico da doença. A IgA por ser produzida em secreção salivar e lacrimal, age como primeiro combate em defesa do organismo (DI FABIO e ROSSINI, 2000; CAVANAGH, 2007).

Diversos fatores influenciam na resposta imune, dentre eles estão a genética, idade da ave, duração de anticorpos maternos, origem da vacina, procedimento de vacinação, combinação de vacinas e integridade do sistema linfoide. O que se sabe sobre a resposta imune contra a infecção do vírus da bronquite é pouco, são necessários mais estudos para obter mais e melhores respostas (DHINAKAR e JONES, 1997; CAVANAGH, 2007).

\section{DIAGNÓSTICO DA DOENÇA}

O diagnóstico para bronquite infecciosa aviária requer testes laboratoriais, e a confirmação ocorre pelo isolamento viral em associação com o resultado da sorologia. O diagnóstico pode ser presuntivo, que é realizado analisando o histórico e os sinais clínicos, porém só é possível fazer essa análise apenas no estágio final da doença. Por esse motivo é necessária a realização de exames laboratoriais (LIMA, 2007; CUBILLOS, 2009).

O diagnóstico direto detecta a presença do agente viral, por meio de microscopia eletrônica e imunofluorescência. Outro teste que pode ser realizado é o de reação em cadeia da polimerase (PCR), é um método sensível e rápido para identificação dos sorotipos virais, é eficaz na 
diferenciação entre o vírus vacinal e de campo (DI FABIO e ROSSINI, 2000; LIMA, 2007).

O diagnóstico indireto é utilizado para detectar aumento nos títulos de anticorpos, seja por infecção de campo ou avaliação da resposta vacinal. Pode ser realizado por isolamento viral através de órgãos infectados, como pulmões, traqueia, rins e tonsilas cecais. No diagnóstico indireto o método mais utilizado é a sorologia, que é feita por meio de diluições seriadas do soro, em que é avaliada a ausência, presença e aumento nos títulos de anticorpos (DI FABIO e ROSSINI, 2000; LIMA, 2007; CUBILLOS, 2009).

$\mathrm{O}$ método sorológico tem boa especificidade e reprodutibilidade dos resultados, o que auxilia o monitoramento de programas vacinais e detecção de infecções a campo (LIMA, 2007).

\section{DIAGNÓSTICO DIFERENCIAL}

Como a bronquite infecciosa é semelhante a outras doenças, é necessário realizar o diagnóstico diferencial para doença de Newcastle, laringotraqueíte e coriza infecciosa; no entanto, existem sinais característicos que auxiliam na diferenciação dessas doenças (DI FÁBIO e ROSSINI, 2000).

A doença de Newcastle é mais severa que a bronquite infecciosa, dependendo do vírus presente sinais neurológicos serão observados (CUBILLOS, 2009).

A laringotraqueíte raramente acomete aves jovens e sua disseminação é lenta. A presença do muco traqueal sanguinolento é mais intenso do que na bronquite (Lima, 2007; CUBILLOS, 2009).
$\mathrm{Na}$ coriza infecciosa é característica a presença de edema facial com descarga nasal serosa, que dificilmente é observada na bronquite infecciosa (DI FÁBIO e ROSSINI, 2000).

$\mathrm{Na}$ bronquite infecciosa ocorre comprometimento do aparelho reprodutivo; quando há queda na qualidade externa e interna do ovo, a doença deve ser diferenciada da síndrome da queda de postura (EDS, egg drop syndrome), que é causada por um adenovírus. Porém, na EDS não ocorre alteração da qualidade interna do ovo e nem alteração na qualidade da albumina (LIMA, 2007; CUBILLOS, 2009).

\section{PREVENÇÃO E CONTROLE DA DOENÇA}

$\mathrm{Na}$ avicultura o controle da bronquite infecciosa tem sido realizado com sucesso considerável, por intermédio da adoção de medidas de biosseguridade e controle sanitário dos plantéis (CAVANAGH, 2007).

Como a principal via de transmissão é a via aérea e o vírus tem capacidade de se espalhar rapidamente, deve-se tentar inibir a transmissão de um galpão para outro, por meio de controle do fluxo de pessoas, troca de roupa e evitar acesso de veículos dentro da área de biosseguridade (DI FÁBIO e ROSSINI, 2000).

Para auxiliar no controle da bronquite infecciosa aviária é importante que se utilize um bom programa de vacinação. Dentre as vacinas utilizadas existem aquelas atenuadas, que garantem melhor imunidade no trato respiratório, porém podem provocar reações; já o outro tipo de vacina é chamado de vacina inativada que não causa reações e garante alto estímulo antigênico, com titulação elevada de anticorpos. O programa de vacinação deve levar em consideração os 
desafios locais e as cepas disponíveis (DI FÁBIO e ROSSINI, 2000; RESENDE, 2003).

A patogenicidade das cepas vacinais é variável de acordo com o tipo de vírus e laboratório. Existem três sorotipos, que são Massachusetts, Arkansas e D274, o único permitido para uso no Brasil é o sorotipo Massachusetts. As cepas mais utilizadas são de origem holandesa, que é Massachusetts H-120 (BIJLENGA, et al., 2004; LIMA, 2007).

Geralmente a vacinação é feita no primeiro dia de vida, ainda no incubatório, mas em casos de alto desafio de campo é necessária a revacinação. Dentre as vacinas aviárias o vírus da bronquite infecciosa é o mais reativo, por esse motivo é importante que a vacinação seja feita de forma correta (LIMA, 2007).

\section{CONSIDERAÇÕES FINAIS}

A produção avícola brasileira vem aumentando sua produtividade, e se destaca-se nos cenários nacional e internacional do agronegócio. Isto ocorre, pela qualidade reconhecida da carne de frango brasileira, e pelo cenário sanitário adequado, sendo considerado modelo dentre os maiores países produtores e exportadores de frango.

A demanda dos mercados (brasileiro e mundial) exige o aumento da produção, sendo que esse aumento, deve estar associado ao avanço tecnológico e sanitário, e acaba por provocar o aumento no número de animais alojados por granja, e este fato, eleva a pressão sanitária e pode favorecer o surgimento de doenças.

Entre estas doenças, a bronquite infecciosa aviária é conhecida por ser altamente contagiosa e gerar elevados prejuízos econômicos ao setor avícola. Várias ações são tomadas em conjunto para evitar que a doença afete os plantéis avícolas, como por exemplo: protocolos de vacinação conforme desafio da região, execução de programas de biosseguridade e monitorias sanitárias durante toda a vida do lote.

É importante que as técnicas de diagnóstico utilizadas sejam assertivas, e que aconteça o desenvolvimento de novos métodos para detecção de novas cepas, o que pode facilitar a criação de novas vacinas.

O ciclo de vida do frango de corte é curto, e por isso, cada detalhe da cadeia produtiva é importante, e deve ser considerada. O controle sanitário e as de medidas de biosseguridade devem ser seguidos rigidamente, desde o sistema produtor de ovos até o produto final no abatedouro.

O país tem conquistado importantes avanços no requisito da saúde dos plantéis, e isto permite que as exportações brasileiras atinjam patamares acima das médias de crescimento mundial, consolidando o país entre os principais países produtores e exportadores de carne de frango e derivados na atualidade.

\section{REFERÊNCIAS}

ABPA - Associação Brasileira de Proteína Animal. Disponível em: 〈abpa-br.com.br/setores/avicultura〉. Acesso em: 06 fev. 2016.

BIJLENGA, G. et al. Development and use of the H strain of avian infectious bronchitis virus from the Netherlands as a vaccine: a review. Avian Pathology. v.33, n.6, p.550-557, 2004. Disponível em: $<$ http://www.tandfonline.com/doi/pdf/10.1080/0307945 0400013154>. Acesso em: 6 fev. 2016.

CAVANAGH, D.; DAVIS, P.J.; COOK, J.K.A. Infectious bronchitis virus: evidence for recombination within the Massachussets serotype. Avian Pathology, v.21, p.401-408, 1992. Disponível em: <http://www.tandfonline.com/doi/pdf/10.1080/0307945 9208418858 >. Acesso em: 6 fev. 2016. 
CAVANAGH, D.; NAQI, S.A. Infectious bronchitis. In: Diseases of Poultry. $10^{\text {th }}$ ed. Ames: Iowa State University Press, 1997. p. 511-26.

CAVANAGH, D. et al. Coronaviruses from pheasants (Phasianus colchicus) are genetically closed related to coronaviruses of domestic fowl (infectious bronchitis virus) and turkeys. Avian Pathol, 2002; 31:81-93. Disponível em:

<http://www.tandfonline.com/doi/pdf/10.1080/0307945 0120106651>. Acesso em: 6 fev. 2016

CAVANAGH, D. Severe acute respiratory syndrome vaccine development: experiences of vaccination against avian infectious bronchitis coronavirus. Avian Pathology, v.32, n.6, p.567-582, 2003. Disponível em: $<$ http://www.tandfonline.com/doi/pdf/10.1080/0307945 0310001621198>. Acesso em: 6 fev. 2016.

CAVANAGH, D. Coronavirus avian infectious bronchitis virus. Veterinary Research, v.38, p.281297, 2007.

Disponível em: <https://hal.archives-ouvertes.fr/hal00902839/document>. Acesso em: 6 fev. 2016.

CHEN, B.Y.; et al. Histopathology and immunohistochemistry of renal lesions due to infectious bronchitis virus in chicks. Avian Pathol., v.25, n.2, p.269-83, 1996. Disponível em: $<$ http://www.tandfonline.com/doi/pdf/10.1080/0307 9459608419141>. Acesso em: 6 fev. 2016.

CHOUSALKAR, K. K.; CHEETHAM, B. F.; ROBERTS, J.R.; Effects of infectious bronchitis virus vaccine on the oviduct of hens. Vaccine, 2009.

CUBILLOS, A. Bronquite Infecciosa Aviária. In: REVOLLEDO, L.; FERREIRA, J.P.A. Patologia Aviária. Barueri: Manole, 2009. cap. 17 p.158-171.

DHINAKAR, R.G.; JONES, R.C. Immunopathogenesis of infection in SPF chicks and comercial broilers of a variant infectious bronchitis virus of economic importance. Avian Pathology, v. 25, p. 481-501, 1996. Disponível em:

<http://www.tandfonline.com/doi/pdf/10.1080/0307945 9608419157>. Acesso em: 6 fev. 2016.

DHINAKAR, R.G.; JONES, R.C. Infectious bronchitis virus: immunopathogenesis of infection in the chicken. Avian Pathology, v26, p. 677-706, 1997. Disponível em:

<http://www.tandfonline.com/doi/pdf/10.1080/0307945 9708419246>. Acesso em 6 fev. 2016

DI FABIO, J.; ROSSINI, L.I. Bronquite infecciosa das galinhas. In: BERCHIERI JÚNIOR, A.; MACARI, M. Doença das aves. Campinas: Facta, 2000. cap. 21 p. 293-300.
DWARS, R.M.; et al. Progression of lesions in the respiratory tract of broilers after single infection with Escherichia coli compared to superinfection with E. coli after infection with infectious bronchitis virus. Veterinary Immunology and Immunopathology, v. 127, n.1-2, p. 65-76. 2009

HIPÓLITO, O.; SILVA, J.M.L.; HSIUNG, H.M. Bronquite infecciosa das galinhas a doença no Brasil. São Paulo, 1979. p. 72.

JACKWOOD, M. W.; HILT, D.A.; CALLISON, S.A. Detection of infectious bronchitis virus by real-time reverse transcriptase-polymerase chain reaction and identification of quasispecies in the Beaudette strain. Avian Diseases, v.47, n.3, p.718-724, 2003.

JORDAN, F.T.W.; PATTISON, M. Enfermedades de las aves. $3^{\mathrm{a}}$ ed. México D.F.: Editorial El Manual Moderno, 1998. p. 522

LIMA, E.T.; Bronquite infecciosa das galinhas. In: ANDREATTI, L. R. Saúde Aviária e Doenças. São Paulo: Roca, 2007. P.256-260.

MAPA - Ministério da Agricultura, Pecuária e do Abastecimento. Manual de Legislação - Programa Nacional de Sanidade Avícola. Brasília, 2017. p. 171241. Disponível em:

<http://www.agricultura.gov.br/arq_editor/file/Aniamal /Manual\%20de\%20Legisla\%C3\%A7\%C3\%A30\%20\%20Sa\%C3\%BAde\%20Animal\%20-\%20low.pdf> Acesso em: 6 fev. 2016

MATTHIJS, M.G.R et al. Course of infection and immune responses in the respiratory tract of IBV infected broilers after superinfection with E. coli. Veterinary Immunology and Immunopathology, v.127, n.1-2, p.77-84, 2009.

MCKINLEY, E.T.; HILT, D.A.; JACKWOOD, M.W. Avian coronavirus infectious bronchitis attenuated live vaccines undergo selection of subpopulations and mutations following vaccination. Vaccine, v.26, p.1274-1284. 2008.

MENDES, A.A.; BRAGA, S.P.E. A Cadeia Produtiva da Carne de Aves no Brasil.

In: MENDES, A.A.; NAAS, A.I.; MACARI, M. Produção de Frangos de Corte.

Campinas: Facta, 2004. p. 1-22

MONTASSIER, M.F.S. et al. Genetic grouping of avian infectious bronchitis virus isolated in Brazil, bases on RT-PCR/RFLP analysis of the $\mathrm{S} 1$ gene. Pesquisa Veterinária Brasileira v.28, n.3, p.190-194, 2008. Disponível em: <http://www.scielo.br/pdf/pvb/v28n3/11.pdf $>$. Acesso em: 6 fev. 2016 
OIE - ORGANIZAÇÃO MUNDIAL DE SAÚDE ANIMAL.

Disponível em: <http://www.oie.int $>$ Acesso em 6 fev. 2016.

RESENDE, J. S. Genotipificação e filogenia de isolados de vírus oriundos de surtos de bronquite infecciosa das galinhas na avicultura industrial do Estado de Minas Gerais, Brasil, no período entre 1972 e 1989. 2003. 163 p. Tese (Doutorado em Medicina Veterinária)-Escola de Veterinária da Universidade Federal de Minas Gerais, Belo Horizonte, 2003. Disponível em:

<http://www.bibliotecadigital.ufmg.br/dspace/bitstream /handle/1843/BUOS-

8FXL2G/c pia de tese de doutorado_de jos s rgio de resende.pdf?sequence $=1>$. Acesso em: 6 fev. 2016

ROCHA, F.R.T. Produção e caracterização de anticorpos monoclonais contra glicoproteína S1 do vírus da bronquite infecciosa das galinhas. 2000. 31 p. Dissertação (Mestrado em Medicina Veterinária)Escola de Veterinária da Universidade Federal de Minas Gerais, Belo Horizonte, 2000. Disponível em: <http://www.bibliotecadigital.ufmg.br/dspace/bitstream /handle/1843/BUDB-

$\underline{\text { 8BVJ7T/disserta_o_de mestrado_de fernanda_rodrig }}$ ues taveira rocha.pdf?sequence $=1>$. Acesso em: 6 fev. 2016

WINTERFIELD, R.W.; ALBASSAM, M.A.

Nephropathogenicity of infectious bronchitis virus. Poultry Science, v.63, p.2358-2363, 1984.

Gabriel Najar Machado de Sousa e Silva

Médico Veterinário. Especialista em Sanidade de Aves (UNOESC).

\begin{tabular}{l}
\hline César Augustus Winck \\
Doutor em Agronegócios (UFRGS), Professor da \\
Universidade do Oeste de Santa Catarina - \\
UNOESC.
\end{tabular}

